\title{
Correction: Allometric relationships between leaf and bulb traits of Fritillaria przewalskii Maxim. grown at different altitudes
}

\section{Ruili Ma, Shengrong Xu, Yuan Chen, Fengxia Guo, Rui Wu}

There is an error in affiliation 1 for authors Ruili Ma and Shengrong Xu. The correct affiliation 1 is: Dingxi Academy of Agricultural Sciences, Dingxi, China.

\section{Reference}

1. Ma R, Xu S, Chen Y, Guo F, Wu R (2020) Allometric relationships between leaf and bulb traits of Fritillaria przewalskii Maxim. grown at different altitudes. PLOS ONE 15(10): e0239427. https://doi.org/10. 1371/journal.pone.0239427 PMID: 33017404

\section{Gopenaccess}

Citation: Ma R, Xu S, Chen Y, Guo F, Wu R (2021) Correction: Allometric relationships between leaf and bulb traits of Fritillaria przewalskii Maxim. grown at different altitudes. PLOS ONE 16(6): e0253352. https://doi.org/10.1371/journal. pone. 0253352

Published: June 10, 2021

Copyright: ๑ $2021 \mathrm{Ma}$ et al. This is an open access article distributed under the terms of the Creative Commons Attribution License, which permits unrestricted use, distribution, and reproduction in any medium, provided the original author and source are credited. 